ISSN 2354-5852

E-ISSN 2579-5783

\title{
Perancangan dan pembuatan aplikasi alih media dokumen rekam medis berbasis web di RSUD dr. R. Soedarsono Pasuruan
}

\author{
Nachrul Jinan', Vita Permatasari ${ }^{1}$ \\ Jurusan Kesehatan, Politeknik Negeri Jembe, Indonesiar ${ }^{l}$ \\ e-mail:vita@polije.ac.id
}

\begin{abstract}
Destruction of medical record documents at the Regional General Hospital Dr. R. Soedarsono Pasuruan has not been done because there is no supporting application to transfer medical record forms that should not be destroyed such as discharge summary forms, resumes, surgery sheets, baby identification, approval sheets, death sheets, and unique cases that occur in patients. The purpose of this research was to design and make an application for transferring media web-based medical record documents to support the retention process and destruction of medical record documents. This media transfer application is able to scan medical record documents directly without the default application scanner, and can filter the list of medical record documents that have entered an inactive period based on the case. The use of auto suggest and auto complete can speed up the process of entering data into this application. The method used in this study is the method of developing the waterfall system, which is a system development method consisting of stages of requirements definition to produce information on system requirements, system design stages and software to produce designs in the form of flowcharts, context diagrams, DFD, and ERD. The implementation phase and unit testing produce parts of the program which are then combined and tested at the stage of system integration and testing. The results of this research are the application of the media supporting the retention process and the destruction of medical record documents that have been tested with the results of the application can be run properly, and has been implemented in the Regional General Hospital of dr. R. Soedarsono Pasuruan.
\end{abstract}

Keywords: hospital, media transfer, medical record, scanner, waterfall

\section{Pendahuluan}

Berdasarkan peraturan menteri kesehatan nomor 269 tahun 2008 rekam medis adalah berkas yang berisikan catatan dan dokumen tentang identitas pasien, pemeriksaan, pengobatan, tindakan, dan pelayanan lainnya yang telah diberikan kepada pasien. Rekam medis dibuat secara lengkap, jelas, dan tertulis atau secara elektronik (Kemenkes RI, 2008). Sebelum melakukan pemusnahan dokumen rekam medis akan dilakukan retensi atau penyusutan rekam medis, retensi ini bertujuan untuk mengurangi jumlah dokumen rekam medis yang semakin bertambah, menyelamatkan rekam medis yang bernilai guna tinggi serta mengurangi dokumen rekam medis yang tidak bernilai guna atau bernilai guna rendah (Depkes RI, 2006). Dokumen rekam medis yang dipertahankan dan bernilai guna tinggi antara lain ringkasan masuk dan keluar, resume, lembar operasi, identifikasi bayi, lembar persetujuan, dan lembar kematian.

Perkembangan teknologi di bidang sistem informasi rumah sakit berdampak positif terhadap pelayanan di dalamnya. Salah satu contoh pemanfaatan perkembangan teknologi di dalam bidang perumahsakitan adalah adanya sistem informasi yang menunjang proses retensi serta alih media dokumen rekam medis, sistem informasi tersebut memudahkan petugas dalam pemilahan dokumen inaktif tanpa membuka kembali dokumen untuk melihat tanggal kunjungan terakhir pasien, serta sistem informasi tersebut menyediakan fasilitas backup dokumen rekam medis dalam bentuk file digital, hal ini dapat menghemat tempat penyimpanan, serta sebagai pengaman fisik dokumen dari segala gangguan seperti kehilangan, dan kerusakan akibat human error, faktor alam seperti bencana, hama maupun faktor lainnya (Laksono, 2017), seperti penelitian yang dilakukan oleh Zulhalim (2013) yang merubah arsip statis menjadi file digital dan disimpan ke dalam sistem informasi.

Sejalan dengan waktu, pasien yang berkunjung ke RSUD dr. R. Soedarsono Kota Pasuruan semakin bertambah, pertambahan pasien ini mengakibatkan dokumen rekam 
medis semakin banyak, dan rak filing yang tersedia masih kurang untuk menyimpan dokumen rekam medis pasien, pada bulan Mei 2018 jumlah dokumen rekam medis pasien aktif sekitar 75.000 berkas, sedangkan kapasitas penyimpanan dari rak filing hanya sekitar 51.450 berkas, kapasitas dari masingmasing jenis rak filing yang ada di RSUD dr. R. Soedarsono Kota Pasuruan dapat dilihat pada tabel 1 berikut ini.

Tabel 1. Kapasitas Rak Filing di RSUD dr. R. Soedarsono Kota Pasuruan Tahun 2018

\begin{tabular}{|c|c|c|c|c|}
\hline \multirow[b]{2}{*}{ Unit } & \multicolumn{2}{|l|}{ Rak } & \multirow{2}{*}{$\begin{array}{l}\text { Standart } \\
\text { Kapasitas } \\
\text { Tiap Rak } \\
\text { (berkas) } \\
\end{array}$} & \multirow{2}{*}{$\begin{array}{l}\text { Total } \\
\text { Standart } \\
\text { Kapasitas } \\
\text { (berkas) }\end{array}$} \\
\hline & Jenis & Jumlah & & \\
\hline \multirow{4}{*}{$\begin{array}{l}\text { Rawat } \\
\text { Jalan } \\
\text { Rawat } \\
\text { Inap }\end{array}$} & $\begin{array}{l}\text { Rak } \\
\text { Kayu }\end{array}$ & 11 & 3.750 & 41.250 \\
\hline & Roll'O & 2 & 2.700 & 5.400 \\
\hline & $\begin{array}{l}\text { Rak } \\
\text { Besi }\end{array}$ & 16 & 300 & 4.800 \\
\hline & & mlah & & 51.450 \\
\hline
\end{tabular}

Sumber: RSUD dr. R. Soedarsono Kota Pasuruan 2018

Tabel 1 Menjelaskan bahwa kapasitas rak filing yang berada di Rumah Sakit Umum Daerah dr. R. Soedarsono Kota Pasuruan masih kurang jika dibandingkan dengan dokumen yang ada di rumah sakit tersebut. Kurangnya kapasitas penyimpanan, mengakibatkan dokumen rekam medis disimpan rapat di dalam rak filing, serta sebagian dokumen rekam medis disimpan dalam kardus di atas rak. Menurut Pratama, dkk. (2012) hal ini dapat mengakibatkan dokumen mudah rusak, dan sulit untuk diambil kembali jika ada pasien lama yang berkunjung. Rusaknya dokumen rekam medis berdampak pada hilangnya infomasi yang terkandung di dalam dokumen rekam medis tersebut, sehingga jika pasien berkunjung kembali, petugas kesehatan tidak dapat melihat informasi terdahulu pasien, seperti riwayat penyakit terdahulu dan alergi terhadap obat-obatan yang diderita oleh pasien. Jumlah dokumen rekam medis rusak di RSUD dr. R. Soedarsono Kota Pasuruan sekitar 20\%, meliputi map atau cover dari dokumen rekam medis tersebut. Penambahan rak filing tidak dapat dilakukan dikarenakan luas ruang filing yang terbatas hanya $26 \mathrm{~m}^{2}$ untuk masingmasing ruang penyimpanan, sehingga retensi dan pemusnahan perlu dilakukan untuk menanggulangi permasalahan tersebut.

Rumah Sakit Umum Daerah dr. R. Soedarsono Kota Pasuruan masih belum melakukan alih media dan retensi dokumen rekam medis sesuai dengan prosedur, karena pada sistem informasi yang digunakan saat ini masih belum terdapat fasilitas alih media dokumen rekam medis, dan peringatan retensi, sehingga proses retensi dilakukan tanpa mencatat nomor rekam medis dari dokumen yang akan dilakukan retensi. Berdasarkan wawancara yang telah dilakukan kepada kepala rekam medis, rumah sakit membutuhkan sistem informasi yang membantu dalam proses alih media dan retensi.

Berdasarkan permasalahan tersebut, maka peneliti melakukan penelitian berupa perancangan dan pembuatan aplikasi alih media dokumen rekam medis di Rumah Sakit Umum Daerah dr. R. Soedarsono Kota Pasuruan. Aplikasi yang dibuat oleh peneliti memiliki fitur untuk mengalihmediakan dokumen rekam medis dalam bentuk file digital dan terdapat fasilitas peringatan retensi sebagai dasar pemilahan dokumen rekam medis inaktif. Dengan adanya aplikasi alih media ini, petugas tidak perlu memilah setiap formulir yang ada di dalam dokumen rekam medis pada saat melakukan retensi, dan jika formulir yang sudah dimusnahkan dibutuhkan sewaktu-waktu, formulir dapat dicetak kembali.

Tujuan dilakukannya penelitian ini adalah merancang dan membuat aplikasi alih media dokumen rekam medis berbasis web dengan menganalisis kebutuhan user, merancang aplikasi alih media dokumen rekam medis dengan membuat flowchart, context diagram, data flow diagram, dan entity relationship diagram, mengimplementasikan desain dengan membuat kode program berbasis web dan menguji setiap unit program yang telah dibuat, mengintegrasikan setiap unit dan menguji aplikasi alih media dokumen rekam medis dengan menggunakan pengujian black box. 


\section{Metode}

Penelitian ini berupa perancangan dan pembuatan aplikasi alih media dokumen rekam medis berbasis web di Rumah Sakit Umum Daerah dr. R. Soedarsono Kota Pasuruan. Penelitian ini menggunakan perancangan dengan metode Waterfall, framework codeigniter, bootstrap, dan scanner.js sebagai javascript pemindai berkas langsung di dalam browser tanpa aplikasi bawaan scanner. Aplikasi yang dibuat dalam penelitian ini berbasis web yang akan diakses secara lokal via jaringan Local Area Network (LAN), sehingga hanya dapat diakses oleh pengguna yang terhubung ke server secara fisik, dengan menggunakan server lokal data pasien yang bersifat rahasia tetap terjaga dari serangan hacker. Server dapat memuat data alih media sekitar 40.000 file digital rekam medis.

Waktu yang diperlukan dalam penelitian ini yaitu selama 6 bulan, dimulai pada bulan Juli 2018 sampai dengan Desember 2018 dengan tempat penelitian di Rumah Sakit Umum Daerah dr. R. Soedarsono Kota Pasuruan, Jalan Dr. Wahidin Sudiro Husodo Nomor $1-4$, Kota Pasuruan. Teknik pengumpulan data yang digunakan adalah wawancara dan observasi. Wawancara dilakukan kepada kepala rekam medis dan dua orang petugas rekam medis di Rumah Sakit Umum Daerah dr. R. Soedarsono Kota Pasuruan untuk mengetahui jumlah dokumen rekam medis, proses retensi yang sudah dilakukan, pemusnahan dokumen rekam medis, serta untuk mengetahui kebutuhan user mengenai aplikasi yang akan dibuat pada penelitian ini. Pengumpulan data dengan cara observasi dilakukan untuk melihat secara langsung ukuran dan kondisi rak, proses assembling serta dokumen rekam medis yang berada di ruang filing.

Gambaran dari sistem yang akan dibuat oleh peneliti berdasarkan permasalahan yang ada di Rumah Sakit Umum Daerah dr. R. Soedarsono Kota Pasuruan dapat dilihat pada gambar 1 berikut ini.

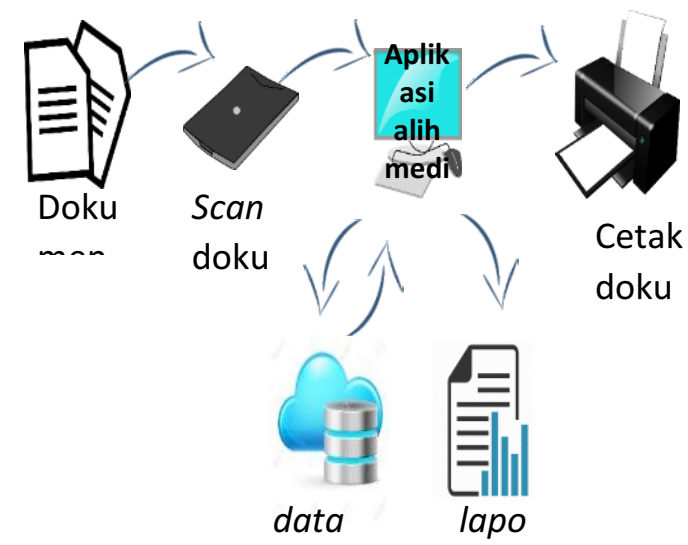

Gambar 1. Gambaran Sistem

Gambar 1 menunjukkan gambaran sistem dari aplikasi alih media dimulai dari dokumen rekam medis yang dipindai langsung oleh aplikasi alih media, kemudian akan disimpan ke dalam database. Data yang sudah tersimpan ke dalam database dapat dijadikan laporan dan juga dapat dicetak kembai jika sewaktu-waktu data diperlukan. Aplikasi alih media dokumen rekam medis dikelola oleh petugas retensi yang juga melakukan proses alih media dokumen rekam medis. Petugas dapat menambahkan data, mengubah data, menghapus data, melihat data, mencetak kembali dan membuat laporan.

Tahapan penelitian dalam penelitian ini dapat dilihat pada gambar 2 berikut ini. 


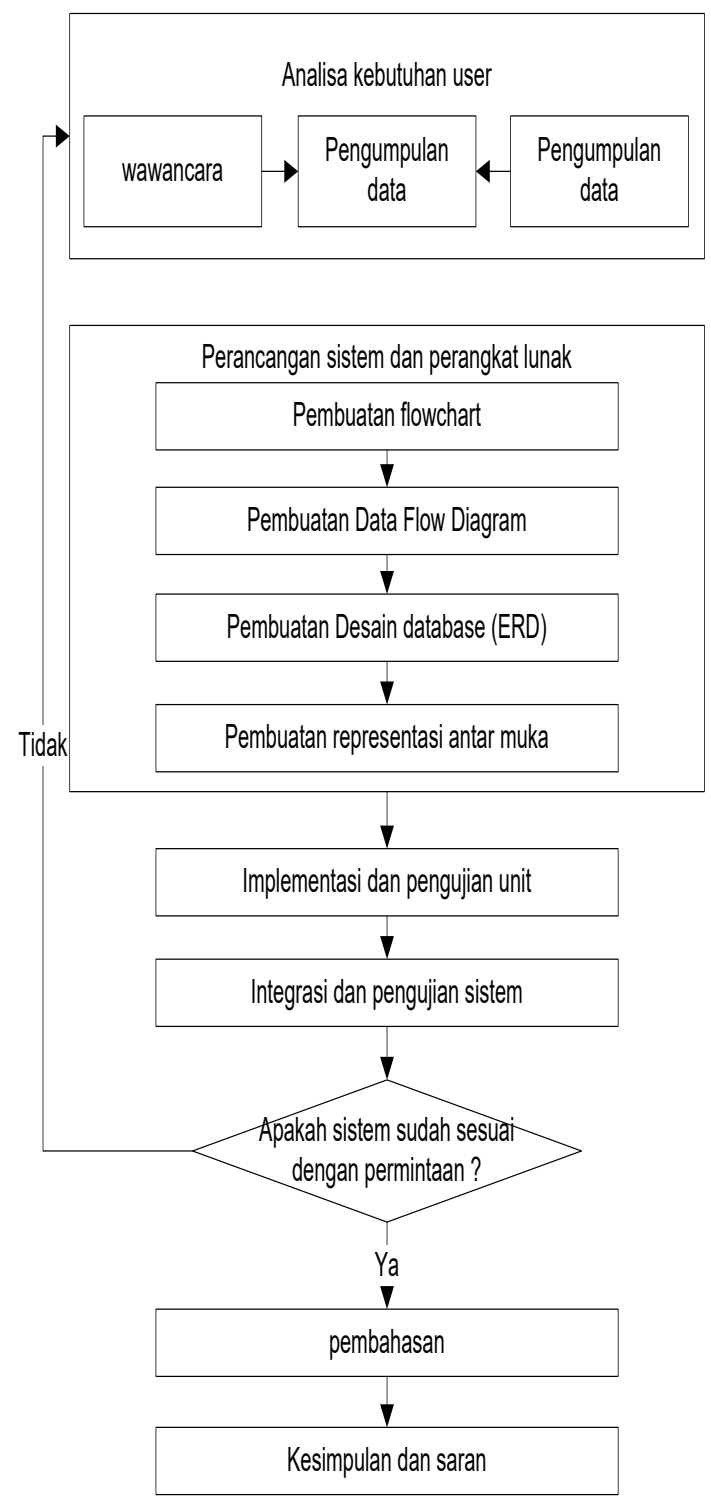

Gambar 2. Tahapan Penelitian

Gambar 2 menunjukkan tahapan penelitian yang dimulai dari analisa kebutuhan user dengan menentukan apa saja fungsi dan prosedur yang diharapkan user dari sistem yang akan dibuat. Desain merupakan tahapan membuat flowchart, Data Flow Diagram, ERD, dan representasi antarmuka. Pengodean menggunakan aplikasi text editor sublime text versi 3.0, dan menggunakan $X A M P P$ versi 3.2.2 sebagai server lokal, dan google chrome sebagai web browser untuk melihat hasil dari pengodean. Pengujian menggunakan pengujian black box untuk menguji aplikasi yang telah dibuat. Implementasi merupakan tahapan dimana aplikasi yang telah jadi, dan telah melalui tahapan pengujian dikirimkan kepada user untuk digunakan. Pembahasan merupakan kegiatan pembahasan hasil penelitian yang ditulis ke dalam bentuk narasi. Kesimpulan dan saran merupakan proses terakhir dari penelitian ini yang bertujuan untuk memberikan kesimpulan mengenai aplikasi yang telah dibuat, dan memberikan saran kepada peneliti agar dapat mengembangkan aplikasi yang lebih baik lagi.

\section{Hasil dan Pembahasan}

Berdasarkan hasil wawancara dan observasi yang telah dilakukan oleh peneliti, kebutuhan fungsional aplikasi alih media dalam penelitian ini adalah menu dashboard, menu pasien, menu kasus, menu admin, menu alih media, menu retensi, menu pemusnahan, menu laporan, menu log aktivitas, dan menu admin. Menu dashboard adalah halaman utama pada saat user/admin berhasil login. Tampilan yang ada di dalam halaman dashboard adalah tampilan jumlah data pasien, jumlah berkas yang sudah dialih mediakan, jumlah berkas yang sudah diretensi, dan jumlah berkas yang sudah dimusnahkan. Menu pasien adalah menu untuk mengelola data pasien. Menu pasien memiliki beberapa fungsi. Berikut adalah fungsi-fungsi yang terdapat di dalam menu pasien:

a. User dapat menambahkan, melihat, mengubah, dan menghapus data pasien sesuai dengan hak akses yang telah diberikan oleh admin.

b. Adanya fitur impor data pasien dalam bentuk Ms. excel yang dihasilkan oleh sistem informasi manajemen rumah sakit.

c. Adanya fitur ekspor data pasien dalam bentuk pdf dan Ms. excel

Menu kasus adalah menu untuk mengelola data kasus. Menu kasus memiliki beberapa fungsi, yakni fungsi untuk menambahkan, melihat, mengubah, dan menghapus data kasus sesuai dengan hak akses yang telah diberikan oleh admin. Menu admin adalah menu yang digunakan untuk mengelola data admin/user aplikasi alih media ini. Menu admin memiliki beberapa fungsi sebagai berikut: 
a. Admin dapat menambahkan, melihat, mengubah, dan menghapus data admin/user.

b. Admin dapat merubah semua data, termasuk foto, level, username dan password, sedangkan user hanya dapat merubah data untuk dirinya sendiri.

c. Admin memberikan hak akses kepada user secara dinamis dengan fasilitas checkbox.

Menu alih media adalah menu untuk mengelola data alih media. Fungsi yang terdapat di dalam menu ini user dapat menambah, melihat, mengubah, dan menghapus data alih media sesuai dengan hak akses yang telah diberikan oleh admin, serta scan berkas pada proses alih media dilakukan langsung di dalam aplikasi. Menu retensi mempunyai fungsi untuk mencetak data berkas yang belum diretensi, serta data berkas yang tidak ditemukan. Menu retensi juga terdapat fasilitas untuk menandai berkas yang sudah diretensi dan berkas yang tidak ditemukan.

Menu pemusnahan mempunyai fungsi untuk mencetak data dokumen rekam medis yang akan dimusnahkan. Data dokumen rekam medis yang sudah dicetak akan hilang dari tampilan, dan masuk ke dalam riwayat pemusnahan. Menu laporan memiliki beberapa fungsi untuk mencetak laporan. Laporan yang dihasilkan adalah laporan alih media, laporan retensi, dan laporan pemusnahan. Setiap laporan akan dicetak berdasarkan kategori kasus, kunjungan terakhir, atau semua kategori. Laporan dapat dicetak dalam bentuk Ms. excel maupun dalam bentuk format pdf.

Menu $\log$ aktivitas adalah menu riwayat aktivitas apa saja yang telah dilakukan oleh user/admin di dalam aplikasi alih media. Menu log aktivitas akan menampilkan beberapa informasi seperti jumlah dokumen yang diretensi, dialih mediakan, dan dimusnahkan oleh user/admin setiap hari. Menu log aktivitas hanya dapat diakses oleh admin. Menu Admin merupakan menu yang hanya diakses oleh admin, yakni kepala rekam medis, dalam menu tersebut, admin dapat melihat, menambahkan, menghapus, merubah data admin, di dalam menu ini juga admin mengatur hak akses untuk user.
Berdasarkan hasil wawancara dan observasi yang telah dilakukan oleh peneliti, kebutuhan non fungsional dalam penelitian ini antara lain:

a. Aplikasi alih media dokumen rekam medis dapat mencegah pengguna yang tidak memiliki hak akses dengan ditambahkannya halaman login.

b. Penggunaan scanner dengan kecepatan tinggi, seperti Brother ADS-2400N, Brother ADS-2100N.

c. Penggunaan internet browser yang direkomendasikan adalah google chrome dan mozilla firefox.

d. Jaringan LAN yang sudah dipasang untuk penggunaan multi user.

Perancangan sistem dan perangkat lunak dalam aplikasi ini menggunakan flowchart system, context diagram, data flow diagram, dan entity relationship diagram. Flowchart system dibagi menjadi 3, yakni flowchart system alih media, flowchart system retensi, dan flowchart system pemusnahan. Context diagram yang dihasilkan memiliki 2 entitas, yakni petugas dan kepala rekam medis. Kepala rekam medis sebagai admin mempunyai hak akses penuh terhadap aplikasi, sedangkan user atau petugas memiliki hak akses yang hanya diberikan oleh admin. Context diagram dapat dilihat pada gambar 3 berikut ini.

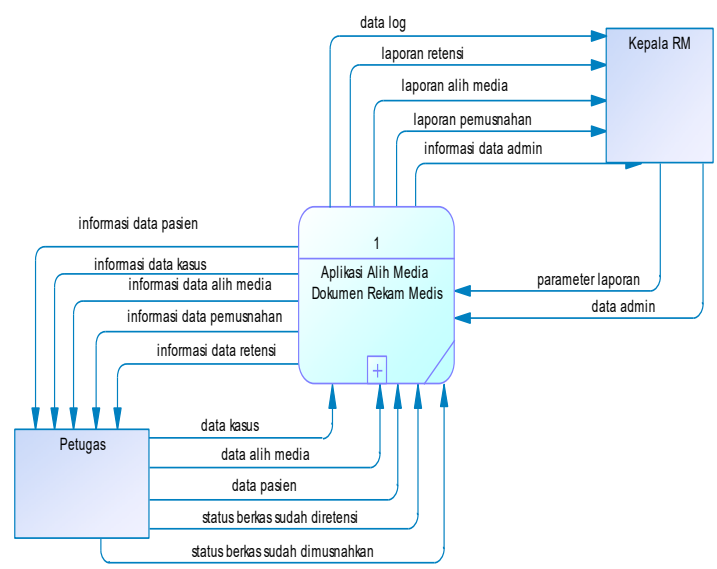

Gambar 3. Context Diagram Aplikasi Alih Media Dokumen Rekam Medis

DFD terbagi menjadi 3 level, level pertama menjabarkan semua alur data dari aplikasi alih media rekam medis, level kedua menjabarkan alur data dari proses alih media, 
ISSN 2354-5852

E-ISSN 2579-5783

retensi, pemusnahan, serta laporan. ERD yang dihasilkan adalah conceptual data model, logical data model, physical data model, dan database aplikasi alih media dokumen rekam medis.

Sebelum memulai menggunakan framework codeigniter, ada beberapa konfigurasi yang harus dilakukan, semua konfigurasi berada di dalam folder application/config/. Konfigurasi pertama adalah mengisikan base url "http://localhost/alihmedia" pada file config.php. Konfigurasi selanjutnya adalah mengisikan beberapa nama library seperti database, dan session, serta mengisikan beberapa nama helper seperti form, url, dan xss pada file autoload.php, fungsi dari mengisikan nama library dan helper pada file autoload.php adalah agar helper dan library dimuat secara otomatis pada saat awal aplikasi digunakan. Konfigurasi selanjutnya adalah mengatur koneksi database, codeigniter sudah menyediakan fasilitas koneksi database, pengguna cukup memasukkan hostname, username, password, dan nama database ke dalam file database.php. setelah dilakukan konfigurasi, dilanjutkan dengan pengkodean program menggunakan bahasa pemrograman html, php, dan javascript.

Integrasi dan pengujian sistem dalam penelitian ini adalah menggabungkan unit-unit program menjadi satu kesatuan aplikasi yang utuh dan dapat digunakan oleh pengguna, kemudian dilakukan pengujian menggunakan pengujian black box. Integrasi dan pengujian sistem dalam penelitian ini dimulai dari halaman depan aplikasi, yaitu halaman dan proses login, kemudian dilanjutkan ke halaman dashboard atau beranda, menu pasien, alih media, kasus, retensi, pemusnahan, laporan, log aktivitas, dan laporan. Pengujian dilakukan oleh pengguna (admin dan user) dan menunjukkan hasil semua fungsi dapat dijalankan dengan baik. Berikut merupakan tampilan aplikasi alih media setelah dilakukan pengujian sistem.

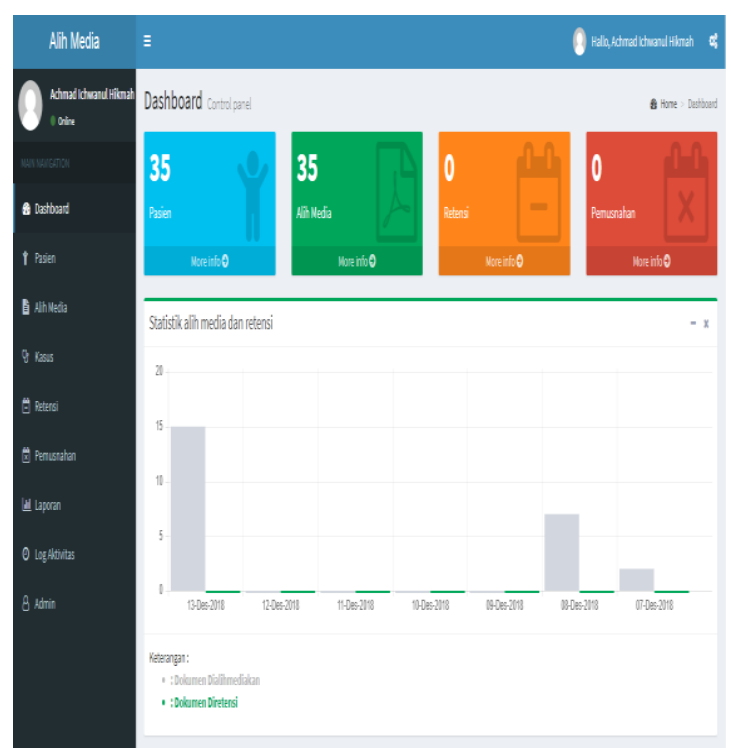

Gambar 4. Tampilan aplikasi alih media dokumen rekam medis

Gambar 4 menunjukkan di dalam aplikasi alih media dokumen rekam medis mempunyai beberapa menu, menu dashboard atau beranda menyajikan informasi mengenai jumlah data pasien, alih media, retensi, data pemusnahan yang sudah diinputkan, serta grafik alih media dan retensi. Gambar proses alih media dokumen rekam medis dapat dilihat pada gambar 5 berikut ini.

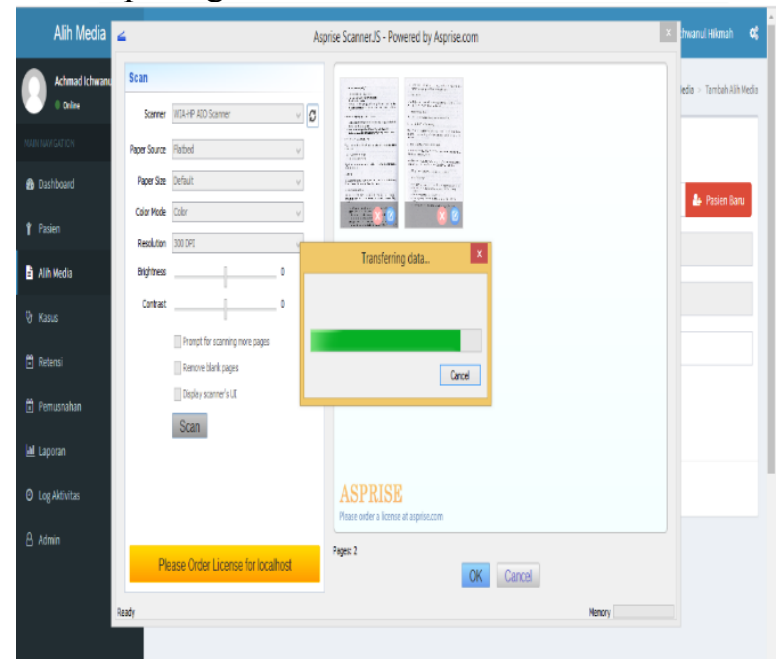

Gambar 5. Proses alih media dokumen rekam medis

Gambar 5 merupakan proses memindai dokumen rekam medis yang dilakukan langsung di dalam aplikasi, setelah dilakukan pemindaian, pengguna dapat mengedit, merubah urutan, memotong, dan 
ISSN 2354-5852

E-ISSN 2579-5783

memutar gambar. Jika sudah selesai, semua gambar akan menjadi satu file berformat .pdf.

Proses implementasi dilakukan

setelah proses pengujian yang diserahkan kepada pengguna. Berdasarkan permintaan pengguna dilakukan perbaikan pada hak akses agar dapat dirubah oleh admin secara dinamis. Setelah dilakukan perubahan dan diserahkan kepada pengguna, aplikasi yang dibangun sudah sesuai dengan kebutuhan pengguna. Berikut merupakan perbandingan hasil implementasi aplikasi alih media dokumen rekam medis dengan proses manual.

Tabel 2. Perbandingan hasil implementasi aplikasi alih media dengan proses retensi dan pemusnahan secara manual

\begin{tabular}{|c|c|c|}
\hline Kategori & $\begin{array}{l}\text { Proses } \\
\text { secara } \\
\text { manual }\end{array}$ & $\begin{array}{l}\text { Proses } \\
\text { menggunakan } \\
\text { aplikasi alih } \\
\text { media }\end{array}$ \\
\hline Kelebihan & $\begin{array}{ll}\text { a. } & \text { Tidak } \\
\text { perlu } \\
\text { memas } \\
\text { ukkan } \\
\text { data } \\
\text { pasien } \\
\text { dan } \\
\text { scan } \\
\text { dokum } \\
\text { en } \\
\text { rekam } \\
\text { medis, } \\
\text { proses } \\
\text { retensi } \\
\text { dilakuk } \\
\text { an } \\
\text { dengan } \\
\text { melihat } \\
\text { tahun } \\
\text { kunjun } \\
\text { gan } \\
\text { terakhi } \\
\text { r yang } \\
\text { beada } \\
\text { di map } \\
\text { dokum } \\
\text { en } \\
\text { rekam } \\
\text { medis }\end{array}$ & $\begin{array}{ll}\text { a. } & \text { Penentuan } \\
\text { dokumen } \\
\text { rekam } \\
\text { medis } \\
\text { inaktif } \\
\text { spesifik dari } \\
\text { tanggal, } \\
\text { bulan, } \\
\text { tahun, serta } \\
\text { kasus. } \\
\text { Memilah } \\
\text { dokumen } \\
\text { rekam } \\
\text { medis } \\
\text { inaktif } \\
\text { dibantu } \\
\text { dengan } \\
\text { menggunaka } \\
\text { n daftar } \\
\text { yang dapat } \\
\text { dicetak dari } \\
\text { sistem } \\
\text { Memilah } \\
\text { dokumen } \\
\text { rekam } \\
\text { medis yang } \\
\text { sudah } \\
\text { memasuki } \\
\text { waktu } \\
\text { pemusnahan } \\
\text { dibantu } \\
\text { dengan } \\
\text { menggunaka } \\
\text { n daftar } \\
\text { yang dapat } \\
\text { dicetak dari } \\
\end{array}$ \\
\hline
\end{tabular}


ISSN 2354-5852

E-ISSN 2579-5783

\begin{tabular}{|c|c|c|}
\hline Kategori & $\begin{array}{l}\text { Proses } \\
\text { secara } \\
\text { manual }\end{array}$ & $\begin{array}{l}\text { Proses } \\
\text { menggunakan } \\
\text { aplikasi alih } \\
\text { media }\end{array}$ \\
\hline & 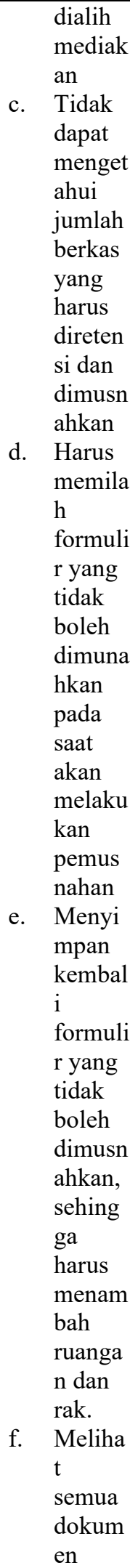 & \\
\hline
\end{tabular}

\begin{tabular}{cll}
\hline \multirow{3}{*}{ Kategori } & $\begin{array}{l}\text { Proses } \\
\text { secara } \\
\text { manual }\end{array}$ & $\begin{array}{l}\text { Proses } \\
\text { menggunakan } \\
\text { aplikasi alih } \\
\text { media }\end{array}$ \\
\hline & yang & \\
berada & \\
di & \\
dalam & \\
rak & \\
setiap & \\
kali & \\
retensi & \\
\hline
\end{tabular}

Perbandingan hasil implementasi aplikasi alih media dengan proses retensi dan pemusnahan secara manual pada tabel 2 di atas menunjukkan bahwa kelebihan dari penggunaan aplikasi alih media dokumen rekam medis lebih banyak daripada tidak menggunakan bantuan aplikasi.

\section{Simpulan dan Saran \\ 4.1 Simpulan}

Berdasarkan hasil dan pembahasan di atas, dari penelitian ini dapat disimpulkan bahwa Definisi persyaratan aplikasi alih media dokumen rekam medis ini telah dilakukan dengan metode wawancara dan observasi, sehingga menghasilkan informasi yang dapat diimplementasikan pada menumenu dalam aplikasi ini, antara lain menu pasien, kasus, admin, alih media, retensi, pemusnahan, laporan, serta log aktivitas. Perancangan sistem dan perangkat lunak dalam aplikasi ini menggunakan flowchart system, context diagram, data flow diagram, dan entity relationship diagram. Flowchart system dibagi menjadi 3, yakni flowchart system alih media, flowchart system retensi, dan flowchart system pemusnahan. Context diagram yang dihasilkan memiliki 2 entitas, yakni petugas dan kepala rekam medis. Kepala rekam medis sebagai admin mempunyai hak akses penuh terhadap aplikasi, sedangkan user atau petugas memiliki hak akses yang hanya diberikan oleh admin. DFD terbagi menjadi 3 level, level pertama menjabarkan semua alur data dari aplikasi alih media rekam medis, level kedua menjabarkan alur data dari proses alih media, retensi, pemusnahan, serta laporan. ERD yang dihasilkan adalah conceptual data model, logical data model, physical data model, serta 
dihasilkan database aplikasi alih media dokumen rekam medis.

Implementasi dan pengujian unit dilakukan dengan mengimplementasikan rancangan yang sudah dibuat ke dalam bentuk program dengan menggunakan bahasa pemrograman web, framework yang digunakan dalam pengimplementasian adalah codeigniter, Admin LTE sebagai template, serta scanner.js sebagai framework pendukung proses scanning berkas rekam medis. Integrasi dan pengujian sistem dilakukan untuk menggabungkan semua unitunit program menjadi satu, kemudian dilakukan pengujian dengan menggunakan black box, yakni pengujian berdasarkan fungsi-fungsi yang ada di dalam aplikasi. Pengujian dilakukan oleh pengguna (admin dan user). Hasil pengujian menunjukkan bahwa semua fungsi berhasil dijalankan dengan baik.

\subsection{Saran}

Saran peneliti yang dapat menjadi bahan pertimbangan jika aplikasi alih media dokumen rekam medis berbasis web ini akan dikembangkan atau diperbaiki Diharapkan data pasien dapat terintegrasi dengan sistem informasi manajemen rumah sakit, agar petugas pada saat melakukan alih media dokumen rekam medis tidak lagi melakukan proses input data pasien.

Diharapkan pada penelitian selanjutnya menggunakan data tabel dengan server side processing, agar dalam menampilkan data yang banyak tidak membuat program menjadi lambat. Pada saat import data pasien, diharapkan pada penelitian selanjutnya menambahkan fungsi review data pasien yang akan diunggah, dan menambahkan tanda pada data-data yang tidak dapat diunggah.

\section{Daftar Pustaka}

Brady, M.,\& Loonam, J., (2010). "Exploring the use of entity-relationship diagramming as a technique to support grounded theory inquiry". Article in Qualitative Research in Organizations and Management An International Journal. 5/3. P. 224 237. http://webpages.dcu.ie/ bradym/ research/00papr03i.pdf

Desember 2018]
Ian Sommerville. (2003), Software Engineering (Rekayasa Perangkat Lunak)/Ian Sommerville; alih bahasa, Dra.Yuhilza Hanum M.Eng, ; Hilarius Wibi Hardani. Ed. 6, Erlangga, Jakarta. https://books.google.co.id/ books?id $=x f 6 i N k O o c U 8 C \& p g=P R 4 \&$ $d q=$ Dra.Yuhilza + Hanum + M.Eng\&hl $=i d \& s a=X \&$ ved $=0$ ahUKEwjmlaC02t vcAhUUU30KHZhVBKYQ6AEIMDA $C \# v=$ onepage $\& q=$ waterfall $\& f=$ false. [8 Agustus 2018]

Jogiyanto, H.M., (2005). Analisa dan Desain Sistem Informasi: Pendekatan Terstruktur Teori dan Praktik Aplikasi Bisnis. Yogyakarya: Andi.

Kementerian Kesehatan RI. (2008). Peraturan Menteri Kesehatan Republik Indonesia Nomor 269/MENKES/PER/III/2008 Tentang Rekam Medis.

(2011). Peraturan Menteri Kesehatan Republik Indonesia Nomor 1171/MENKES/PER/VI/2011

Tentang Sistem Informasi Rumah Sakit.

. (2013). Peraturan Menteri Kesehatan Republik Indonesia Nomor 82 Tahun 2013 Tentang Sistem Informasi Manajemen Rumah Sakit.

Laksono, R. (2017). "Pemanfaatan Teknologi Digital Dalam Proses Alih Media Arsip Statis”. Jurnal Diplomatika, 1/1, Hal. 47 - 60. https://jurnal.ugm.ac.id/diplomatika/a rticle/download/28271/17235. [12 Mei 2018]

Pratama, T.W.Y., F. Hikmah, dan N. Nuraini. "Perencanaan Kebutuhan Rak Penyimpanan Berkas Rekam Medis di Rumah Sakit PTP N X (Persero) Jember". Dalam publikasi ilmiah. http://e-journal. stikesmuhbojonegoro.ac.id/index.php/ stikes/article/view/74/46. [ [1 Juni 2018] 
ISSN 2354-5852

E-ISSN 2579-5783

Zulhalim. (2013). "Desain dan Implementasi Aplikasi Alih Media Arsip Statis Menggunakan Visual Basic.Net, SQL Server, dan Crystal Report (Studi Kasus: Sistem Informasi Manajemen Arsip Plus di Badan Perpustakaan Arsip Daerah Propinsi DKI Jakarta)". Dalam Jurnal Manajemen Informatika,

http://www.jayakarta.ac.id/jurnal/ jurnal_zul_arsip.pdf. $\quad[1 \quad$ Agustus 2018] 